The FASEB Journal express article 10.1096/fj.04-2513fje. Published online January 27, 2005.

\title{
Short-term hyperglycemia produces oxidative damage and apoptosis in neurons
}

\author{
Andrea M. Vincent, Lisa L. McLean, Carey Backus, and Eva L. Feldman \\ University of Michigan, Department of Neurology Ann Arbor, Michigan 48109 \\ Corresponding author: Andrea M. Vincent, Ph.D., University of Michigan, Department of \\ Neurology, 4414 Kresge III, 200 Zina Pitcher Place, Ann Arbor, MI 48109. E-mail: \\ andreav@umich.edu
}

\section{ABSTRACT}

Dorsal root ganglia neurons in culture die through programmed cell death when exposed to elevated glucose, providing an in vitro model system for the investigation of the mechanisms leading to diabetic neuropathy. This study examines the time course of programmed cell death induction, regulation of cellular antioxidant capacity, and the protective effects of antioxidants in neurons exposed to hyperglycemia. We demonstrate that the first $2 \mathrm{~h}$ of hyperglycemia are sufficient to induce oxidative stress and programmed cell death. Using fluorimetric analysis of reactive oxygen species (ROS) production, in vitro assays of antioxidant enzymes, and immunocytochemical assays of cell death, we demonstrate superoxide formation, inhibition of aconitase, and lipid peroxidation within $1 \mathrm{~h}$ of hyperglycemia. These are followed by caspase- 3 activation and DNA fragmentation. Antioxidant potential increases by $3-6 \mathrm{~h}$ but is insufficient to protect these neurons. Application of the antioxidant $\alpha$-lipoic acid potently prevents glucoseinduced oxidative stress and cell death. This study identifies cellular therapeutic targets to prevent diabetic neuropathy. Since oxidative stress is a common feature of the micro- and macrovascular complications of diabetes, the present findings have broad application to the treatment of diabetic patients.

Key words: reactive oxygen species • dorsal root ganglion • diabetic neuropathy

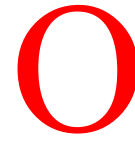

ur laboratory is focused on understanding the pathogenesis of microvascular complications of diabetes, with a focus on neuropathy (1). At present, improvement of glycemic control remains the only therapeutic strategy to prevent or delay the onset or progression of diabetic neuropathy (2). Hyperglycemia in animal and in vitro models of diabetes activates a number of enzymatic and nonenzymatic pathways of glucose metabolism that are implicated in the development of neuropathy. These include 1) increased polyol pathway activity leading to sorbitol and fructose accumulation, $\mathrm{NAD}(\mathrm{P})$-redox imbalances, and changes in signal transduction; 2) nonenzymatic glycation of proteins yielding "advanced glycation end-products" (AGEs); 3) activation of protein kinase $\mathrm{C}$ (PKC), initiating a cascade of stress responses; 4) increased hexosamine pathway flux; and 5) hyperglycemia-mediated superoxide overproduction by the mitochondrial electron transfer chain (3-5). Each of these mechanisms result in reactive oxygen species (ROS), reflected in an overall increased state of cellular oxidative stress. 
Inhibition of ROS, as well as maintenance of euglycemia, may restore metabolic and vascular imbalances and block both the initiation and progression of neuropathy $(3,6)$.

We have reported that apoptosis occurs in dorsal root ganglion (DRG) neurons and Schwann cells of diabetic rats. Approximately $30 \%$ of DRG from diabetic rats express cleaved capsase-3 and are TUNEL positive (7). Electron microscopy demonstrates that DRG from diabetic animals contain swollen mitochondria with disrupted inner cristae structure (7). Our observations of apoptosis and loss of neurons in the DRG of diabetic animals agree with the findings of other laboratories (8-11). Free radicals are produced in DRG neurons exposed to hyperglycemia and parallel the development of mitochondrial dysfunction. After hyperglycemia, DRG neurons display mitochondrial membrane depolarization, release of mitochondrial cytochrome $c$, caspase activation, DNA degradation, and chromatin condensation $(11,12)$.

We have also demonstrated that mitochondrial dysfunction and apoptosis seen in diabetic rats can be recapitulated in an in vitro cell culture model $(7,13)$. Examination of DRG neurons in culture permits the examination of pathologic and neuroprotective mechanisms that closely reflect the responses of neurons in the whole animal (14). Our in vitro approach allows us to ask and answer mechanistic questions that are not possible in animal models. The current study further explores the mechanisms underlying glucose-mediated cell death in DRG neurons in culture. We can then return to the animal model and perform genetic manipulations to test the relevance of these mechanisms in vivo. In the cell culture model, oxidative stress is evident within $2 \mathrm{~h}$ of hyperglycemia. The DRG neurons respond to glucose-mediated oxidative stress by maintaining glutathione levels and increasing the antioxidant enzymes superoxide dismutase (SOD) and catalase after $3 \mathrm{~h}$. Yet, this response is insufficient; within $2 \mathrm{~h}$ of hyperglycemia, DRG neurons activate cell death pathways. In contrast, exogenous antioxidants $\alpha$-lipoic acid and catalase together can prevent hyperglycemia-induced oxidative stress and cell death. Thus, rapid hyperglycemia-induced oxidative stress is a critical mediator of DRG neuron injury. The study strongly indicates the use of antioxidants in the prevention of diabetic neuropathy, as well as targeting secondary mechanisms of regulation of the innate antioxidant response and inhibition of hyperglycemia-induced NADH oxidase activity.

\section{MATERIALS AND METHODS}

\section{DRG culture model of hyperglycemia}

DRG were harvested from embryonic day 15 Sprague-Dawley rats, dissociated in 1\% trypsin, and then cultured on rat-tail collagen-coated culture plates in growth media. All culture reagents were from Gibco (Grand Island, NY) unless stated otherwise. Growth media was prepared using Neurobasal medium supplemented with $1 \times$ B-27 additives, 50 ng/ml NGF (Harlan Bioscience, Indianapolis, IN), $40 \mu \mathrm{M}$ FUDR (Sigma, St Louis, MO), and 1,000 U/ml penicillin/streptomycin/neomycin $(\mathrm{ABX})$ solution. Initial plating medium contains $2 \mu \mathrm{M}$ glutamine. DRG neurons were re-fed after $24 \mathrm{~h}$ in fresh media containing all additives except glutamine. On day 2, cells were rinsed then re-fed using treatment media (neurobasal media containing $4 \mathrm{ng} / \mathrm{ml}$ selenium, $4 \mathrm{ng} / \mathrm{ml}$ hydrocortisone, $0.01 \mathrm{mg} / \mathrm{ml}$ transferrin, $3 \mathrm{ng} / \mathrm{ml} \beta$ estradiol, $50 \mathrm{ng} / \mathrm{ml} \mathrm{NGF,} 40 \mu \mathrm{M}$ FUDR, and ABX). Experiments were performed on DRG neurons on day 3 in culture in the absence of B-27 additives. Neurobasal medium contains a basal $25 \mathrm{mM}$ glucose that was essential for DRG neuron culture (7). Previous studies 
demonstrate that lower concentrations of glucose also induce DRG neuron death in culture and that hyperglycemic insult leading to DRG neuron death was produced at greater than $35 \mathrm{mM}$ total glucose (7). To produce a hyperglycemic insult, $20 \mathrm{mM}$ additional glucose (yielding a total $45 \mathrm{mM}$ glucose) was added to the media for the period specified in individual experiments. Media glucose concentrations do not significantly decrease during the treatment periods as determined by mass spectrometry.

\section{Antioxidant treatment of DRG neurons}

$\alpha$-Lipoic acid is a potent antioxidant that is in clinical trials for diabetic neuropathy $(15,16)$. Many reagents, when dissolved in growth media, release hydrogen peroxide (17). This can confound the study of their protective effects in cell culture by producing a pro-oxidant effect. Catalase is an enzyme that breaks down hydrogen peroxide, and so the freshly dissolved $\alpha$-lipoic acid was treated with catalase to remove hydrogen peroxide before applying to the cultures as follows. $\alpha$-Lipoic acid was initially dissolved at $0.5 \mathrm{M}$ in DMSO and then diluted to $1 \mathrm{mM}$ in treatment media. Lyophilized catalase $(1,000 \mathrm{U} / \mathrm{ml})$ was then added and the solution was incubated at $37^{\circ} \mathrm{C}$ for $30 \mathrm{~min}$. The solution was added to growth media in the culture plates at a 1:10 dilution, giving a final concentration of $100 \mu \mathrm{M} \alpha$-lipoic acid.

\section{Cleavage of caspase-3}

To detect caspase-3 staining, paraformaldehyde (4\%)-fixed DRG neurons were stained with 0.1 $\mu \mathrm{g} / \mathrm{ml}$ anti-cleaved caspase-3 (PharMingen, San Diego, CA) and $7.5 \mu \mathrm{g} / \mathrm{ml}$ Texas red conjugated goat anti-rabbit antibody (Molecular Probes, Eugene, OR) for $1 \mathrm{~h}$, as described previously (7, 18). The nuclear chromatin was counterstained with $1 \mu \mathrm{g} / \mathrm{ml}$ bisbenzamide in PBS. The specificity of the antibody was determined by immunoabsorbing against caspase-3 peptide. Neurons were considered to have active caspase-3 if staining can be clearly localized to the neuronal cytosol using fluorescence microscopy.

\section{Fragmentation of genomic DNA}

TdT mediated dUTP-biotin nick end labeling (TUNEL) staining was used to detect programmed cell death in DRG neurons. DRG neurons were fixed in 4\% paraformaldehyde before staining. Samples were labeled with digoxygenin-dUTP and then stained with horseradish peroxidaseconjugated anti-digoxygenin antibody using a kit according to the manufacturer's instructions (Intergen, Gaithersburg, MD).

\section{Measurement of superoxide formation using dihydroethidium}

The cell permeant dihydroethidium (DHE; Molecular Probes) was used to assess real-time formation of superoxide in DRG neurons. Reduced DHE emits blue fluorescence. Exposure to superoxide causes oxidation to ethidium that displays red fluorescence. Stock DHE was dissolved at a concentration of $10 \mathrm{mg} / \mathrm{ml}$ in DMSO, diluted to $150 \mu \mathrm{M}$ in HEPES-buffered saline solution (HBSS: $10 \mathrm{mM}$ HEPES, pH 7.4, $150 \mathrm{mM} \mathrm{NaCl}, 5 \mathrm{mM} \mathrm{KCl}, 1 \mathrm{mM} \mathrm{MgCl}, 1.8 \mathrm{mM}$ $\mathrm{CaCl}_{2}$ ) immediately before use, then added directly to the culture media at a 1:50 dilution, giving a final concentration of $3 \mu \mathrm{M}$. The DHE solution was applied to DRG neurons for the final 15 min of an experiment, and then neurons were rinsed once rapidly in HBSS and immediately 
placed in a fluorescence plate reader (Fluroskan Ascent II, Labsystems, Helsinki). For each sample, the ratio of red (518 nm excitation, $605 \mathrm{~nm}$ emission) over blue (485 excitation, 520 emission) fluorescence was determined with $1 \mathrm{~s}$ integration for each reading.

\section{Protein concentration}

For many of the biochemical assays that follow, enzyme activity or other parameters were normalized to the amount of protein in the sample. The protein concentration was determined by the Bradford-Lowry method using the reagents and protocol supplied by Bio-Rad. Samples were read in a 96-well plate in an absorbance plate reader (Multiskan, Labsystems, Helsinki, Finland).

\section{Aconitase activity assay}

DRG neuron lysates were prepared at different times after the application of $20 \mathrm{mM}$ glucose, and then aconitase activity was assessed by cofactor recycling using a kit according to the manufacturer's protocol (Oxis Research, Bioxytech, Portland, OR).

\section{Thiobarbituric acid reactive substance}

Lipid peroxidation was assessed by determining the level of thiobarbituric acid reactive substance (TBARS) in cell lysates. DRG neurons were lysed in water, and then $100 \mu$ sample was added to $200 \mu \mathrm{l}$ ice-cold $10 \%$ trichloroacetic acid on ice for 15 min to precipitate protein. During this incubation, standards were prepared using 1,1,3,3-tetramethoxypropane in the range of $0-100 \mu \mathrm{M}$. Precipitated samples were centrifuged at $2,200 \mathrm{~g}$ for $15 \mathrm{~min}$ at $4^{\circ} \mathrm{C}$. Supernatants were mixed with an equal volume of $0.67 \%$ thiobarbituric acid and then boiled for $10 \mathrm{~min}$. Once cooled the absorbance was read at $532 \mathrm{~nm}$ on an absorbance plate reader (Multiskan, Labsystems, Helsinki, Finland).

\section{Assessment of 8-isosprostane F2a}

Standard Western blotting procedures were used to determine the relative levels of 8-isoprostane in DRG neuron lysates (19). An antibody against 8-isoprostane F2 $\alpha$ was obtained from Cayman Chemical Co. (Ann Arbor, MI). This antibody detects a specific band in a gel that represents 8isoprostane attached in a protein complex. When cell lysates were spiked with purified 8isoprostane F2 $\alpha$, the band was increased, but the band was not detectable when 8-isoprostane alone was loaded on the gel (data not shown). The band was lost when the antibody was preabsorbed with an excess of 8-isoprostane $\mathrm{F} 2 \alpha$. The nitrocellulose membranes were incubated with $5 \mu \mathrm{g} / \mathrm{ml}$ primary antibody overnight at $4^{\circ} \mathrm{C}$. Secondary anti-rabbit immunoglobulin antibody was conjugated to horseradish peroxidase diluted 1:3000 (Santa Cruz Biotechnology, Santa Cruz, CA) and incubated for $1 \mathrm{~h}$ at room temperature. Bands were visualized with enhanced chemiluminescence (Amersham), and exposed to film (Hyperfilm-ECI, Amersham). Densitometry of imaged bands was performed using NIH Image 1.6 software. Bands representing 8-isoprostane F2 $\alpha$ were corrected for background and for differences in loading determined by probing for GAPDH. 


\section{Reduced glutathione}

Concentrations of reduced glutathione (GSH) were measured in cell lysates by use of a kit according to the manufacturer's protocol (Cayman Chemical, Ann Arbor, MI).

\section{Total radical antioxidant potential}

Total radical antioxidant potential (TRAP) was determined by a luminometric method (20). DRG neurons were lysed in ultra-pure water and then sonicated to complete the breakdown of cellular structures. Lysates were centrifuged at $10,000 \mathrm{~g}$ for $5 \mathrm{~min}$, then $5 \mu \mathrm{l}$ of lysate was loaded on a 96-well plate, serial doubling dilutions of a further $5 \mu \mathrm{l}$ aliquot were also loaded in wells of the 96-well plate; $200 \mu \mathrm{l}$ of luminol (ECL, Amersham, Arlington Heights, IL) were added, followed by $50 \mu$ of the oxidizing agent $100 \mathrm{mM}$ 2,2'-azobis(amidinopropane) dihydrochloride (ABAP). The plate was immediately placed in a luminometric plate reader (Fluoroskan Ascent II, Labsystems, Helsinki, Finland) and the mean lag to the ABAP-induced oxidation of luminol that was attributed to the antioxidant potential of the cell lysate was measured by plotting luminescence against time (20).

\section{DRG neuron fractionation}

To assess TRAP in mitochondria and cytosol of DRG neurons, the cells were first fractionated by ultracentrifugation. DRG neurons were scraped off the culture surface in $10 \mathrm{mM}$ HEPES/ $\mathrm{NaOH}$, pH 7.4 containing $10 \mu \mathrm{g} / \mathrm{ml}$ aprotinin, $10 \mu \mathrm{g} / \mathrm{ml}$ leupeptin, $10 \mu \mathrm{g} / \mathrm{ml}$ PMSF, 250 $\mathrm{mM}$ sucrose, $1 \mathrm{mM}$ EGTA, and $1 \mathrm{mM}$ EDTA. The lysate was passed through a 28 -gauge needle several times to shear the plasma membranes. Plasma membranes were pelleted at $1,500 \mathrm{~g}$ for 5 min. The supernatant was centrifuged at $10,000 \mathrm{~g}$ for $15 \mathrm{~min}$ to pellet mitochondria. The mitochondrial pellet was rinsed three times to remove residual supernatant (cytosol).

\section{SOD activity}

The total SOD activity in cell lysates was determined using a kit according to the manufacturer's protocol (Oxis Research, Bioxytech).

\section{Catalase activity}

Catalase activity in DRG neuron lysates was determined by assessing the ability of lysates to prevent hydrogen peroxide-induced oxidation of Amplex Red, per the protocol published by the manufacturer (Molecular Probes).

\section{NADH oxidase}

NADH oxidase activity in DRG neuron lysates was assessed through the rate of oxidation of added NADH, by measuring the absorbance at $340 \mathrm{~nm}$ (21). DRG neurons were scraped in 50 $\mathrm{mM}$ Tris-MES buffer, $\mathrm{pH} 7.4$ containing $10 \mu \mathrm{g} / \mathrm{ml}$ leupeptin and $10 \mu \mathrm{g} / \mathrm{ml}$ phenyl-methylsulfonyl-fluoride (PMSF), sonicated, centrifuged at $10,000 \mathrm{~g}$ for $5 \mathrm{~min}$, then assayed immediately. To inhibit NADH oxidase, diphenylene iodonium (DPI) was added to the lysate at a final concentration of $100 \mu \mathrm{M}$. 


\section{Statistical analysis}

All experimental samples were assayed in duplicate in each protocol. Assays were repeated on thee separate occasions using different DRG neuron cultures. Statistical significance was determined using ANOVA with $95 \%$ confidence intervals.

\section{RESULTS}

\section{A short exposure to hyperglycemia is sufficient to induce programmed cell death in DRG neurons}

We have previously demonstrated that long-term exposure to $20 \mathrm{mM}$ extra glucose produces mitochondrial dysfunction, oxidative stress, and initiation of programmed cell death in DRG neurons $(7,13)$. The present study was designed to further define the mechanisms that lead to glucose-induced DRG neuron injury. Recent studies have demonstrated that alterations in extracellular glucose are more detrimental to various complication-prone cell types in culture than a constant exposure to high glucose $(22,23)$. To determine the degree of DRG neuron injury produced by short periods of hyperglycemia, the development of caspase- 3 cleavage at $6 \mathrm{~h}$ (Fig. $\underline{1 A})$ or TUNEL staining at $24 \mathrm{~h}$ (Fig. 1B) was compared in DRG neurons exposed to $20 \mathrm{mM}$ added glucose for the first $2 \mathrm{~h}$ only or for the duration of the experiment. There were nearly identical levels of DRG neuron death at the end-point with a $2 \mathrm{~h}$ glucose exposure compared with prolonged hyperglycemia for the whole 6 or $24 \mathrm{~h}$ time course of the experiment. These results then led us to examine the cellular mechanisms that are activated within $2 \mathrm{~h}$ of hyperglycemia that mediate the initiation of programmed cell death.

\section{Hyperglycemia produces oxidative stress}

We previously demonstrated oxidative stress in DRG neurons undergoing glucose-induced programmed cell death (13). If oxidative stress mediates glucose-induced cell death in the DRG neurons, we would expect to find evidence of oxidative stress within the critical initial $2 \mathrm{~h}$ period of hyperglycemia. Therefore, early evidence of enzyme inhibition and lipid peroxidation were assessed in DRG neurons exposed to $20 \mathrm{mM}$ added glucose. Aconitase is an enzyme in the TCA cycle that is exquisitely sensitive to superoxide (24). In the presence of superoxide, the critical $\mathrm{Fe}^{2+}$ ion is released, which reversibly inhibits the enzyme activity. Application of $20 \mathrm{mM}$ added glucose, but not the nonmetabolizable mannitol $(20 \mathrm{mM})$ significantly decreases aconitase activity in DRG neurons within $1 \mathrm{~h}$ and the activity does not recover over $5 \mathrm{~h}$ (Fig. 2).

Malondialdehyde and 8-isoprostane F2 $\alpha$ are two widely described products of ROS-mediated lipid peroxidation (25). The TBARS assay (Fig. 3A) measures the amount of malondialdehyde in cell lysates. TBARS increases significantly in DRG neurons within $1 \mathrm{~h}$ of the application of 20 $\mathrm{mM}$ glucose. This effect is specific for glucose; the same concentration of mannitol does not produce an increase in TBARS. Exposure to $20 \mathrm{mM}$ added glucose increases the amount of 8 isoprostane $\mathrm{F} 2 \alpha$ within $1 \mathrm{~h}$, and this persists at $5 \mathrm{~h}$ in the blot compared with the loading control GAPDH (Fig. 3B and $\underline{C}$ ). Densitometry indicates that $1 \mathrm{~h}$ exposure to $20 \mathrm{mM}$ glucose increases the level of 8-isoprostane F2 $\alpha$ threefold compared with control conditions. Again, the development of oxidative stress is caused by extra glucose and not through osmotic shock, since the effect is not reproduced by the addition of $20 \mathrm{mM}$ mannitol. 


\section{Activation of NADH oxidase suggests that glucose-induced neuron injury occurs in the mitochondria}

Overloading the electron transfer chain with reduced substrates from the TCA cycle, such as $\mathrm{NADH}$, leads to activation of the mitochondrial enzyme NADH oxidase to regenerate NAD+ (3). In several injury systems, activation of NADH oxidase may be the major source of superoxide radicals $(22,26)$. In DRG neurons, NADH oxidase activity increases fourfold within $1 \mathrm{~h}$ after the application of $20 \mathrm{mM}$ glucose. The level of NADH oxidase activity decreases at the $3 \mathrm{~h}$ period, but a second slower peak of NADH oxidase activation is observable at the $5 \mathrm{~h}$ period, at a sevenfold higher level than baseline activity (i․ . 4A) .

We next confirmed that NADH oxidase injures DRG neurons through superoxide formation. DRG neuron lysates were prepared for the NADH oxidase assay, $3 \mu \mathrm{M}$ DHE was then added, and the rate of DHE oxidation was assessed over several minutes. A duplicate set of samples was also prepared with the specific NADH oxidase inhibitor diphenylene iodonium (DPI), so that residual superoxide formation in these samples would be attributable to a source other than NADH oxidase (Fig. 4B). Two peaks of superoxide are observable at 1 and $5 \mathrm{~h}$ after the application of $20 \mathrm{mM}$ glucose. The early peak of superoxide is only modestly decreased when NADH oxidase is inhibited, suggesting that while some NADH oxidase activity is present, a significant amount of superoxide is formed in the DRG neurons from a source other than NADH oxidase. In contrast, the slower, $5 \mathrm{~h}$ peak of superoxide is almost entirely abolished in the presence of NADH oxidase inhibition. Thus, the second peak of superoxide formation at $5 \mathrm{~h}$ following the application of $20 \mathrm{mM}$ glucose is attributable to the activation of NADH oxidase.

\section{DRG mount an antioxidant response}

The second, $5 \mathrm{~h}$ peak in NADH oxidase activity led us to question whether DRG neurons respond to glucose-induced oxidative stress by altering other types of protein activities. More specifically, we examined whether DRG neurons alter antioxidant enzyme expression during hyperglycemia-induced oxidative stress. The ability to regulate innate antioxidant capacity may provide a novel therapeutic target against neuronal loss in diabetes (27). To explore the potential for DRG neurons to mount an antioxidant response, the activities of two antioxidant enzymes were examined, as well as the level of cellular reduced glutathione. The activities of total SOD, the enzyme that detoxifies superoxide radicals, or catalase that breaks down hydrogen peroxide $\left(\mathrm{H}_{2} \mathrm{O}_{2}\right)$, were measured over the time course of glucose-induced DRG neuron injury (Fig. 5). Basal SOD activity in cultured DRG neurons is $\sim 50 \mathrm{U} / \mathrm{mg}$ protein, which is relatively high compared with published values in nerve (Fig. 5A). After application of $20 \mathrm{mM}$ glucose, there is a small but statistically significant increase in SOD activity at the $3 \mathrm{~h}$ period to $68 \pm 4 \mathrm{U} / \mathrm{mg}$ protein that returns to baseline after $5 \mathrm{~h}$. Catalase activity is moderate at baseline in the cultured DRG neurons with $20 \pm 2 \mathrm{U} / \mathrm{mg}$ protein (Fig. $5 B$ ). Similar to SOD, catalase increases to a peak 3 $\mathrm{h}$ after application of $20 \mathrm{mM}$ glucose, then declines rapidly to baseline. The peak in catalase is highly significant, with a fivefold increase in activity over the baseline to $99 \pm 5 \mathrm{U} / \mathrm{mg}$ protein.

Reduced glutathione (GSH) was assessed in the DRG neurons at increasing times following the application of $20 \mathrm{mM}$ glucose. Basal GSH in the cultured DRG neurons is $18.1 \pm 3.0 \mu \mathrm{mol} / \mathrm{mg}$ protein (Fig. 5C). There is no rapid decrease in GSH to correspond with the early production of superoxide (compare with Fig. 4B). Between 1-3 h after application of $20 \mathrm{mM}$ glucose, there is a 
modest decrease in GSH to $10.8 \pm 2 \mu \mathrm{mol} / \mathrm{mg}$ protein. There is no further change in the level of GSH over the remainder of the time course. This suggests that, while superoxide is generated, and lipid peroxides increase, the surviving DRG neurons maintain the ability to recycle GSH.

\section{Antioxidants prevent ROS formation and DRG neuron programmed cell death}

If rapid development of oxidative stress is a mediator of the death of DRG neurons, then antioxidants may protect DRG neurons during a hyperglycemic insult. $\alpha$-lipoic acid is a potent antioxidant that may slow the progression of diabetic neuropathy in patients (28). To remove the $\mathrm{H}_{2} \mathrm{O}_{2}$ produced when $\alpha$-lipoic acid was dissolved in culture media (see Materials and Methods), the $\alpha$-lipoic acid solution was treated with catalase. Because $\alpha$-lipoic acid produces $\mathrm{H}_{2} \mathrm{O}_{2}$ (17) and because catalase is unlikely to be taken up by cultured DRG neurons, application of either of these agents alone does not protect DRG neurons against glucose-induced injury (Fig. 6A). Treatment with $\alpha$-lipoic acid alone is, in fact, toxic to the DRG neurons. When DRG neurons are treated with catalase-treated $\alpha$-lipoic acid overnight $(16 \mathrm{~h})$ before the application of $20 \mathrm{mM}$ glucose, the activation of caspase 3 after the application of $20 \mathrm{mM}$ glucose is completely prevented (Fig. 6A).

To ensure that the antioxidant treatment prevents oxidative stress, superoxide generation was assessed by exposing the DRG neurons to $20 \mathrm{mM}$ added glucose for increasing periods of time, then loading with $3 \mu \mathrm{M}$ DHE. Oxidation of DHE in intact DRG neurons was determined in a fluorescence plate-reader by measuring the ratio of red ethidium fluorescence to blue DHE fluorescence (Fig. 6B). Similar to previous studies, application of $20 \mathrm{mM}$ glucose produced a slow rise in superoxide by $5 \mathrm{~h}$. Using the sensitive fluorimetric analysis, we now observed a rapid transient peak in superoxide within $1 \mathrm{~h}$ after the glucose application. In DRG neurons that were pretreated for $16 \mathrm{~h}$ with the antioxidants $\alpha$-lipoic acid plus catalase, not only the glucoseinduced peak in superoxide, but also the basal level of superoxide was significantly decreased. Application of $20 \mathrm{mM}$ mannitol rather than glucose did not alter superoxide production at any time compared with untreated control DRG neurons.

Further examination of the ability of the antioxidant treatment to prevent DRG neuron programmed cell death is illustrated in Fig. 6C and $\underline{D}$ with DRG neurons exposed to $20 \mathrm{mM}$ added glucose for $24 \mathrm{~h}$ in the presence or absence of $16 \mathrm{~h}$ preincubation with catalase-treated $\alpha$ lipoic acid. Neurons are fixed and TUNEL stained. Examination of the DRG neurons by light microscopy reveals that $24 \mathrm{~h}$ after the application of $20 \mathrm{mM}$ glucose there is evidence of condensed chromatin, nuclear DNA fragmentation (TUNEL positive) and beading of the neurites (Fig. 6C). These changes were completely prevented when $20 \mathrm{mM}$ glucose was added in the presence of antioxidant pretreatment. TUNEL staining was quantitated by counting the percent TUNEL positive neurons in each condition (Fig. 6D). Exposure to $20 \mathrm{mM}$ glucose increased TUNEL positivity from $\sim 20 \%$ in untreated control cells to $78 \pm 3 \%$ after $24 \mathrm{~h}$. Antioxidant treatment alone did not alter DRG neuron survival. Pretreatment with the antioxidants completely prevented glucose-induced DRG neuron DNA fragmentation, with TUNEL positivity decreased from $78 \pm 3$ to $24 \pm 3 \%$. 


\section{Antioxidant treatment directly promotes the antioxidant potential of DRG neurons}

The rapid evidence of oxidative stress in DRG neurons, as well as the potent ability for exogenous antioxidants to protect against glucose-induced programmed cell death, suggests that these cells have little intrinsic capacity to defend against oxidative stress. Therefore, the antioxidant capacity of the DRG neurons was examined during the development of injury in the presence of $20 \mathrm{mM}$ added glucose with and without antioxidant pretreatment (Fig. 7). The total TRAP assay measured the total capacity of a sample to prevent a chain of oxidative reactions. TRAP was assessed in DRG neurons over the first $5 \mathrm{~h}$ after the application of $20 \mathrm{mM}$ glucose, the time course when superoxide increases (Fig. 7A). Basal TRAP in the DRG neurons was 14.5 $\pm 3.0 \mathrm{U} / \mu \mathrm{g}$ protein. Over the $5 \mathrm{~h}$ period, there was a trend to increase total TRAP, but this increase was not statistically significant. When DRG neurons were preincubated for $16 \mathrm{~h}$ with the antioxidant catalase-treated $\alpha$-lipoic acid, total TRAP increased from $14.5 \pm 3 \mathrm{U} / \mu \mathrm{g}$ protein to $42.9 \pm 2 \mathrm{U} / \mu \mathrm{g}$ protein. There was no significant change in TRAP over the time course after application of $20 \mathrm{mM}$ glucose in the antioxidant-treated DRG neurons.

Despite evidence that there was a modest increase in SOD and catalase and only a small decrease in $\mathrm{GSH}$, the fact that the total antioxidant potential did not decrease in the presence of glucoseinduced oxidative stress was surprising. Since the injurious oxidative stress after hyperglycemia is hypothesized to occur in the mitochondria, the DRG neurons were fractionated by ultracentrifugation, and then TRAP was assessed in the mitochondrial and cytosolic fractions. This assay requires a large number of cells per condition, so we chose to limit our experiments to a $3 \mathrm{~h}$ time course (Fig. 7B). Separation of mitochondria and cytosol was demonstrated by Western blotting for the mitochondrial marker COX-IV and the cytosolic marker lactate dehydrogenase (not shown). The increase in TRAP was observed in the cytosolic fraction and was more marked than the increase in TRAP in the whole cell lysate. In contrast, TRAP in the mitochondrial fraction decreased by the $3 \mathrm{~h}$ period, suggesting that exposure to hyperglycemia that injures DRG neurons can specifically produce oxidative stress in the mitochondria. Thus, it is likely the prevention of this mitochondrial oxidative stress through the pretreatment with catalase-treated $\alpha$-lipoic acid protects DRG neurons against hyperglycemia-induced cell death.

\section{DISCUSSION}

These studies in DRG neurons provide compelling evidence that acute hyperglycemic episodes can cause neuronal cell death through a mechanism that involves oxidative stress in the mitochondria. Notably, a $2 \mathrm{~h}$ period of exposure to $20 \mathrm{mM}$ added glucose is as severe as $24 \mathrm{~h}$, producing equal levels of DRG neuron death. In clinical diabetes, transient peaks of hyperglycemia underlie the early development of microvascular complications and present a significant challenge to both the patient and physician $(29,30)$. The continual tight control of blood glucose is the most effective means of preventing diabetic complications (6). In parallel, in cell culture, periodic fluctuations in glucose are more detrimental to cells than constant exposure to increased glucose levels, as observed in large vein endothelial cells (22), mesangial cells (31), and tubulointerstitial cells (23). Although our work is focused on DRG neurons, our findings may have broader application to an increased understanding of diabetic macrovascular disease, nephropathy, and retinopathy $(32,33)$. 
By comparing the timelines for changes in enzyme systems, oxidative stress, and evidence of programmed cell death in cell culture (Fig. 8), we can propose a mechanism for increasing injury by fluctuating glucose levels. In DRG neurons, the switch to high glucose rapidly produces oxidative stress that can injure neurons within $2 \mathrm{~h}$, probably through mitochondrial stress $(3,13)$. Yet, the neurons rapidly adapt through feedback mechanisms on these metabolic pathways, loss of aconitase, and rapid increases in antioxidant enzyme activity. Remaining at high glucose levels, then, would not produce additional stress on the cells, as they have adapted to the high glucose insult. However, a return to low glucose would promote the restoration of the glycolytic pathway and a decrease in the antioxidant enzymes so that another switch to high glucose will produce a second burst of oxidative stress and thus a greater accumulated injury.

If oxidative stress mediates the induction of DRG neuron injury, then we should find evidence of oxidative stress within the critical $2 \mathrm{~h}$ period of hyperglycemia that leads to cell death. In the current study, aconitase activity was rapidly and irreversibly lost within $1 \mathrm{~h}$ after the application of $20 \mathrm{mM}$ glucose but not mannitol. This suggests that hyperglycemia-induced superoxide generation rapidly inhibits the TCA cycle and that this is a metabolic effect unrelated to osmotic stress. There is some evidence that aconitase is decreased in animal models of diabetes (34), but this enzyme is not widely studied in vivo, probably because it is difficult to extract intact.

Lipid peroxidation is a widely used biomarker of cellular oxidative stress (19). Many clinical and in vivo animal models of diabetes use the TBARS assay to determine lipid peroxidation in tissue and biological fluids (reviewed in ref 27). There are no published data on TBARS on cell culture models of hyperglycemia, although lipid peroxidation is documented in glucose-exposed ex vivo nerve tissue (35) and in cultures exposed to AGEs (36). In animal models, TBARS is elevated after $6 \mathrm{wk}$ of diabetes in the small intestine (37), brain (38), liver, and pancreas (39). Plasma TBARS is elevated in diabetic patients (40). Thus the current data showing a steady rise in TBARS following the application of $20 \mathrm{mM}$ glucose is consistent with the concept that hyperglycemia produces lipid peroxidation in DRG neurons that could contribute to neuropathy. The data also confirm that oxidative stress is present within the first critical $2 \mathrm{~h}$ period of hyperglycemia.

Our data implicate NADH oxidase in the sustained production of superoxide in DRG neurons exposed to elevated glucose. This enzyme is involved in hyperglycemia-induced macrovascular disease (22) and diabetic nephropathy (26) through the generation of superoxide. NADH oxidase also contributes to microvascular deficits in diabetic rats and inhibition of the enzyme significantly improves nerve blood flow after 6 wk of diabetes (41). Although the NAD+:NADH ratio is unbalanced in the nerve of diabetic rats (42), few studies have directly explored the role of NADH oxidase in the pathogenesis of diabetic neuropathy. Taken together, these data suggest that NADH oxidase could be an important therapeutic target in the treatment of diabetic neuropathy.

The early increase in cytosolic TRAP, with a concomitant decrease in mitochondrial TRAP, suggests that mitochondria are key sites of glucose-mediated injury. Although DRG neurons increase cytosolic antioxidant enzymes, this increase is insufficient to prevent injury. Our data suggest that the mitochondria are less able to prevent glucose-induced oxidative stress, probably because this is the main site for free radical generation in hyperglycemia $(13,43)$. Thus, 
mitochondrial stress is likely to produce hyperglycemia-induced DRG neuron death and consequently provides an intracellular target for antioxidant therapy.

Another means of preventing neuropathy through glucose-mediated oxidative stress may involve manipulation of the innate antioxidant response of the cells. The present study demonstrates a modest increase in cytosolic antioxidant potential in the presence of hyperglycemia that is insufficient, and probably too late, to prevent neuron death. We also demonstrate an increase, again albeit late as well as transient, in the antioxidant enzymes SOD and catalase in these cells. Changes in antioxidant enzymes have been widely studied in diabetic rats, although the data are conflicting. Generally, SOD increases in diabetic animals in the liver $(39,44)$. Kidney SOD increases in some studies (45) but decreases in others (39). In the brain and heart, SOD activity decreases $(46,47)$. In contrast, catalase is decreased in most diabetic tissues (47). The current study may help to explain the variable SOD results observed in animal models of diabetes. The DRG neurons may have a higher steady state of SOD activity in the pro-oxidant culture system than is reported in vivo (see Fig. $5 \mathrm{~A}$ and ref 48), but they retain the ability to respond to a hyperglycemic insult. Thus, even in nontreated diabetic rats, SOD activity is likely to rapidly alter with eating and with other stress cues.

The innate ability of cells to activate an oxidative stress response is an area of intense research activity (49). Small molecule mediators that promote antioxidant status directly in neurons may provide an exciting new avenue for therapy against diabetic neuropathy. SOD mimetics are under investigation in diabetes complications and so far, these have been found effective against hyperglycemia-induced apoptosis in the retina (27).

Since these therapies targeting the innate oxidative stress response are early in development, exogenous antioxidants remain the most promising avenue for the prevention of diabetic neuropathy $(1,27)$. Consistent with many other studies we demonstrate that antioxidants can potently prevent hyperglycemia-induced oxidative stress and cell death in culture (50). Studies of $\alpha$-lipoic acid in animal and cell culture models demonstrate decreases in both oxidative stress and in diabetes-induced changes in endogenous antioxidant systems $(35,39,47)$. The understanding that antioxidants may prevent complications has led to the broad use of $\alpha$-lipoic acid in diabetic patients in Europe (16). An additional benefit of $\alpha$-lipoic acid for type 2 diabetes is its ability to promote insulin sensitivity $(51,52)$.

The maintenance of nondiabetic levels of SOD and catalase in the presence of exogenous antioxidants is particularly interesting. This is most likely explained by the large increase in TRAP that we observe in the presence of $\alpha$-lipoic acid and catalase treatment that would blunt the cellular response to free radical generation. The clinical implication of these findings is that combined therapies that directly boost the innate antioxidant enzyme systems as well as supply increased cellular antioxidant potential will provide superior protection against peaks of oxidative stress during periods of hyperglycemia.

Our demonstration that a brief, $2 \mathrm{~h}$, exposure to hyperglycemia is sufficient to produce significant cell death in DRG neurons is consistent with accumulating clinical data. Some degree of neuropathy is eventually diagnosed in $>50 \%$ of diabetic patients and only intensive glycemia control is known to decrease this incidence (6). Often, painful diabetic neuropathy is the presenting symptom for type 2 diabetes (53), and patients with impaired glucose tolerance 
develop neuropathy that cannot be attributed to other metabolic impairments (29). While our in vitro model produces a very acute injury, we note that clinical diabetes can take years to develop. This difference can be explained by considering that the in vivo system is more complex than the more homogeneous cell population obtained after 3 days in culture. In culture all the cells are simultaneously exposed to the insult. In vivo, we expect fewer cells to be exposed to the acute insult through spatial separation. In addition, our system does not consider the possibility that neurons can regenerate (54). Even in the culture system, we never kill all of the neurons, and we cannot extrapolate this reduction in numbers of cell bodies to predict when clinical symptoms in man will occur. Despite this difference between our in vitro model and clinical or experimental diabetes, we have identified many parallel changes in oxidative stress and antioxidant systems. This study has prompted ongoing efforts to develop new mouse models of diabetes complications through neuronal specific manipulations of antioxidant enzymes such as SOD and glutathione synthetases. At present, we are breeding mice with Cre-linked promoters for neuronal nestin with mice that have lox-linked target antioxidant enzymes.

In summary, oxidative stress is a critical target for therapeutic intervention in diabetic neuropathy and impaired glucose tolerance. Both increasing the nerve expression of antioxidant enzymes and the application of antioxidants will be beneficial. In addition, inhibition of superoxide-producing enzymes such as NADH oxidase may be another important therapeutic target. Combining these approaches will provide a new avenue of therapy for patients with neuropathy due to diabetes and impaired glucose tolerance.

\section{ACKNOWLEDGMENTS}

The authors would like to thank Judith Boldt for excellent secretarial assistance. This work was supported by the Juvenile Diabetes Research Foundation Center for the Study of Complications in Diabetes and the National Institutes of Health (RO1 NS38849) (Eva L. Feldman) and the Program for Understanding Neurological Diseases.

\section{REFERENCES}

1. Feldman, E. L. (2003) Oxidative stress and diabetic neuropathy: a new understanding of an old problem. J. Clin. Invest. 111, 431-433

2. Zochodne, D. W. (1999) Diabetic neuropathies: features and mechanisms. Brain Pathol. 9, 369-391

3. Brownlee, M. (2001) Biochemistry and molecular cell biology of diabetic complications. Nature 414, 813-820

4. Du, X. L., Edelstein, D., Rossetti, L., Fantus, I. G., Goldberg, H., Ziyadeh, F., Wu, J., and Brownlee, M. (2000) Hyperglycemia-induced mitochondrial superoxide overproduction activates the hexosamine pathway and induces plasminogen activator inhibitor-1 expression by increasing Sp1 glycosylation. Proc. Natl. Acad. Sci. USA 97, 12222-12226

5. Nishikawa, T., Edelstein, D., Du, X. L., Yamagishi, S., Matsumura, T., Kaneda, Y., Yorek, M. A., Beebe, D., Oates, P. J., Hammes, H. P., et al. (2000) Normalizing mitochondrial 
superoxide production blocks three pathways of hyperglycaemic damage. Nature 404, 787790

6. Feldman, E. L., Stevens, M. J., Russell, J. W., and Greene, D. A. (2002) Somatosensory neuropathy. In Ellenberg and Rifkin's Diabetes Mellitus (Porte, D., Jr., Sherwin, R. S., and Baron, A., eds) pp. 771-788, McGraw Hill

7. Russell, J. W., Sullivan, K. A., Windebank, A. J., Herrmann, D. N., and Feldman, E. L. (1999) Neurons undergo apoptosis in animal and cell culture models of diabetes. Neurobiol. Dis. 6, 347-363

8. Srinivasan, S., Stevens, M. J., and Wiley, J. W. (2000) Diabetic peripheral neuropathy: Evidence for apoptosis and associated mitochondrial dysfunction. Diabetes 49, 1932-1938

9. Kishi, M., Tanabe, J., Schmelzer, J. D., and Low, P. A. (2002) Morphometry of dorsal root ganglion in chronic experimental diabetic neuropathy. Diabetes 51, 819-824

10. Kishi, M., Mitsui, M., Nagamatsu, M., Nickander, K. K., Schmelzer, J. D., Tanabe, J., Yao, J. K., and Low, P. A. (2001) Dorsal root ganglion pathology in chronic experimental diabetic neuropathy. J. Periph. Nerv. Syst. 6, 152-153

11. Schmeichel, A. M., Schmelzer, J. D., and Low, P. A. (2003) Oxidative injury and apoptosis of dorsal root ganglion neurons in chronic experimental diabetic neuropathy. Diabetes 52, $165-171$

12. Cheng, C., and Zochodne, D. W. (2003) Sensory neurons with activated caspase-3 survive long-term experimental diabetes. Diabetes 52, 2363-2371

13. Russell, J. W., Golovoy, D., Vincent, A. M., Mahendru, P., Olzmann, J. A., Mentzer, A., and Feldman, E. L. (2002) High glucose induced oxidative stress and mitochondrial dysfunction in neurons. FASEB J. 16, 1738-1748

14. Zochodne, D. W., Verge, V. M., Cheng, C., Sun, H., and Johnston, J. (2001) Does diabetes target ganglion neurones? Progressive sensory neurone involvement in long-term experimental diabetes. Brain 124, 2319-2334

15. Haak, E., Usadel, K. H., Kusterer, K., Amini, P., Frommeyer, R., Tritschler, H. J., and Haak, T. (2000) Effects of alpha-lipoic acid on microcirculation in patients with peripheral diabetic neuropathy. Exp. Clin. Endocrinol. Diabetes 108, 168-174

16. Ametov, A. S., Barinov, A., Dyck, P. J., Hermann, R., Kozlova, N., Litchy, W. J., Low, P. A., Nehrdich, D., Novosadova, M., O'Brien, P. C., et al. (2003) The sensory symptoms of diabetic polyneuropathy are improved with alpha-lipoic acid: the SYDNEY trial. Diabetes Care 26, 770-776

17. Halliwell, B. (2003) Oxidative stress in cell culture: an under-appreciated problem? FEBS Lett. 540, 3-6 
18. Srinivasan, A., Roth, K. A., Sayers, R. O., Shindler, K. S., Wong, A. M., Fritz, L. C., and Tomaselli, K. J. (1998) In situ immunodetection of activated caspase-3 in apoptotic neurons in the developing nervous system. Cell Death Differ. 5, 1004-1016

19. Vincent, A. M., Russell, J. W., Low, P., and Feldman, E. L. (2003) Oxidative stress in the pathogenesis of diabetic neuropathy. Endocr. Rev. 25, 612-628

20. Alho, H., Leinonen, J. S., Erhola, M., Lonnrot, K., and Aejmelaeus, R. (1998) Assay of Antioxidant Capacity of Human Plasma and CSF in Aging and Disease. Restor. Neurol. Neurosci. 12, 159-165

21. Xia, R., Webb, J. A., Gnall, L. L., Cutler, K., and Abramson, J. J. (2003) Skeletal muscle sarcoplasmic reticulum contains a NADH-dependent oxidase that generates superoxide. Am. J. Physiol. Cell Physiol. 285, C215-C221

22. Quagliaro, L., Piconi, L., Assaloni, R., Martinelli, L., Motz, E., and Ceriello, A. (2003) Intermittent high glucose enhances apoptosis related to oxidative stress in human umbilical vein endothelial cells: the role of protein kinase $\mathrm{C}$ and $\mathrm{NAD}(\mathrm{P}) \mathrm{H}$-oxidase activation. Diabetes 52, 2795-2804

23. Jones, S. C., Saunders, H. J., Qi, W., and Pollock, C. A. (1999) Intermittent high glucose enhances cell growth and collagen synthesis in cultured human tubulointerstitial cells. Diabetologia 42, 1113-1119

24. Patel, M., Day, B. J., Crapo, J. D., Fridovich, I., and McNamara, J. O. (1996) Requirement for superoxide in excitotoxic cell death. Neuron 16, 345-355

25. Pratico, D. (2001) In vivo measurement of the redox state. Lipids 36, Suppl., S45-S47

26. Li, J. M., and Shah, A. M. (2003) ROS generation by nonphagocytic NADPH oxidase: potential relevance in diabetic nephropathy. J. Am. Soc. Nephrol. 14, S221-S226

27. Maritim, A. C., Sanders, R. A., and Watkins, J. B., III (2003) Diabetes, oxidative stress, and antioxidants: a review. J. Biochem. Mol. Toxicol. 17, 24-38

28. Srinivasan, P., Vadhanam, M. V., Arif, J. M., and Gupta, R. C. (2002) A rapid screening assay for antioxidant potential of natural and synthetic agents in vitro. Int. J. Oncol. 20, 983-986

29. Singleton, J. R., Smith, A. G., Russell, J. W., and Feldman, E. L. (2003) Microvascular complications of impaired glucose tolerance. Diabetes 52, 2867-2873

30. Sumner, C. J., Sheth, S., Griffin, J. W., Cornblath, D. R., and Polydefkis, M. (2003) The spectrum of neuropathy in diabetes and impaired glucose tolerance. Neurology 60, 108-111

31. Takeuchi, A., Throckmorton, D. C., Brogden, A. P., Yoshizawa, N., Rasmussen, H., and Kashgarian, M. (1995) Periodic high extracellular glucose enhances production of collagens III and IV by mesangial cells. Am. J. Physiol. 268, F13-F19 
32. Obrosova, I. G., Minchenko, A. G., Vasupuram, R., White, L., Abatan, O. I., Kumagai, A. K., Frank, R. N., and Stevens, M. J. (2003) Aldose reductase inhibitor fidarestat prevents retinal oxidative stress and vascular endothelial growth factor overexpression in streptozotocin-diabetic rats. Diabetes 52, 864-871

33. Obrosova, I. G., and Stevens, M. J. (1999) Effect of dietary taurine supplementation on GSH and $\mathrm{NAD}(\mathrm{P})$-redox status, lipid peroxidation, and energy metabolism in diabetic precataractous lens. Invest. Ophthalmol. Vis. Sci. 40, 680-688

34. Boquist, L., Ericsson, I., Lorentzon, R., and Nelson, L. (1985) Alterations in mitochondrial aconitase activity and respiration, and in concentration of citrate in some organs of mice with experimental or genetic diabetes. FEBS Lett. 183, 173-176

35. Nickander, K. K., McPhee, B. R., Low, P. A., and Tritschler, H. (1996) Alpha-lipoic acid: Antioxidant potency against lipid peroxidation of neural tissues in vitro and implications for diabetic neuropathy. Free Radic. Biol. Med. 21, 631-639

36. Bassi, A. M., Ledda, S., Valentini, S., De Pascale, M. C., Rossi, S., Odetti, P., and Cottalasso, D. (2002) Damaging effects of advanced glycation end-products in the murine macrophage cell line J774A.1. Toxicol. In Vitro 16, 339-347

37. Bhor, V. M., Raghuram, N., and Sivakami, S. (2004) Oxidative damage and altered antioxidant enzyme activities in the small intestine of streptozotocin-induced diabetic rats. Int. J. Biochem. Cell Biol. 36, 89-97

38. Kucukatay, V., Agar, A., Yargicoglu, P., Gumuslu, S., and Aktekin, B. (2003) Changes in somatosensory evoked potentials, lipid peroxidation, and antioxidant enzymes in experimental diabetes: effect of sulfur dioxide. Arch. Environ. Health 58, 14-22

39. Dincer, Y., Telci, A., Kayali, R., Yilmaz, I. A., Cakatay, U., and Akcay, T. (2002) Effect of alpha-lipoic acid on lipid peroxidation and anti-oxidant enzyme activities in diabetic rats. Clin. Exp. Pharmacol. Physiol. 29, 281-284

40. Turk, H. M., Sevinc, A., Camci, C., Cigli, A., Buyukberber, S., Savli, H., and Bayraktar, N. (2002) Plasma lipid peroxidation products and antioxidant enzyme activities in patients with type 2 diabetes mellitus. Acta Diabetol. 39, 117-122

41. Cotter, M. A., and Cameron, N. E. (2003) Effect of the NAD(P)H oxidase inhibitor, apocynin, on peripheral nerve perfusion and function in diabetic rats. Life Sci. 73, 18131824

42. Obrosova, I. G., Van Huysen, C., Fathallah, L., Cao, X., Stevens, M. J., and Greene, D. A. (2000) Evaluation of alpha(1)-adrenoceptor antagonist on diabetes-induced changes in peripheral nerve function, metabolism, and antioxidative defense. FASEB J. 14, 1548-1558

43. Vincent, A. M., Olzmann, J. A., Brownlee, M., Sivitz, W. I., and Russell, J. W. (2004) Uncoupling proteins prevent glucose-induced neuronal oxidative stress and programmed cell death. Diabetes 53, 726-734 
44. Yildirim, O., and Buyukbingol, Z. (2002) Effects of supplementation with a combination of cobalt and ascorbic acid on antioxidant enzymes and lipid peroxidation levels in streptozocin-diabetic rat liver. Biol. Trace Elem. Res. 90, 143-154

45. Limaye, P. V., Raghuram, N., and Sivakami, S. (2003) Oxidative stress and gene expression of antioxidant enzymes in the renal cortex of streptozotocin-induced diabetic rats. Mol. Cell. Biochem. 243, 147-152

46. Grillo, C. A., Piroli, G. G., Rosell, D. R., Hoskin, E. K., Mcewen, B. S., and Reagan, L. P. (2003) Region specific increases in oxidative stress and superoxide dismutase in the hippocampus of diabetic rats subjected to stress. Neuroscience 121, 133-140

47. Maritim, A. C., Sanders, R. A., and Watkins, J. B., III (2003) Effects of alpha-lipoic acid on biomarkers of oxidative stress in streptozotocin-induced diabetic rats. J. Nutr. Biochem. 14, 288-294

48. Guegan, C., Ceballos-Picot, I., Chevalier, E., Nicole, A., Onteniente, B., and Sola, B. (1999) Reduction of ischemic damage in NGF-transgenic mice: correlation with enhancement of antioxidant enzyme activities. Neurobiol. Dis. 6, 180-189

49. Nguyen, T., Sherratt, P. J., and Pickett, C. B. (2003) Regulatory mechanisms controlling gene expression mediated by the antioxidant response element. Annu. Rev. Pharmacol. Toxicol. 43, 233-260

50. Kowluru, R. A., and Koppolu, P. (2002) Diabetes-induced activation of caspase-3 in retina: effect of antioxidant therapy. Free Radic. Res. 36, 993-999

51. Saengsirisuwan, V., Perez, F. R., Sloniger, J. A., Maier, T., and Henriksen, E. J. (2004) Interactions of exercise training and alpha-lipoic acid on insulin signaling in skeletal muscle of obese Zucker rats. Am. J. Physiol. Endocrinol. Metab. 287, E529-E536

52. Bitar, M. S., Wahid, S., Pilcher, C. W., Al Saleh, E., and Al Mulla, F. (2004) Alpha-lipoic acid mitigates insulin resistance in Goto-Kakizaki rats. Horm. Metab. Res. 36, 542-549

53. Polydefkis, M., Griffin, J. W., and McArthur, J. (2003) New insights into diabetic polyneuropathy. JAMA 290, 1371-1376

54. Apfel, S. C. (1999) Nerve regeneration in diabetic neuropathy. Diabetes Obes. Metab. 1, 311

Received July 13, 2004; accepted November 29, 2004. 
Fig. 1
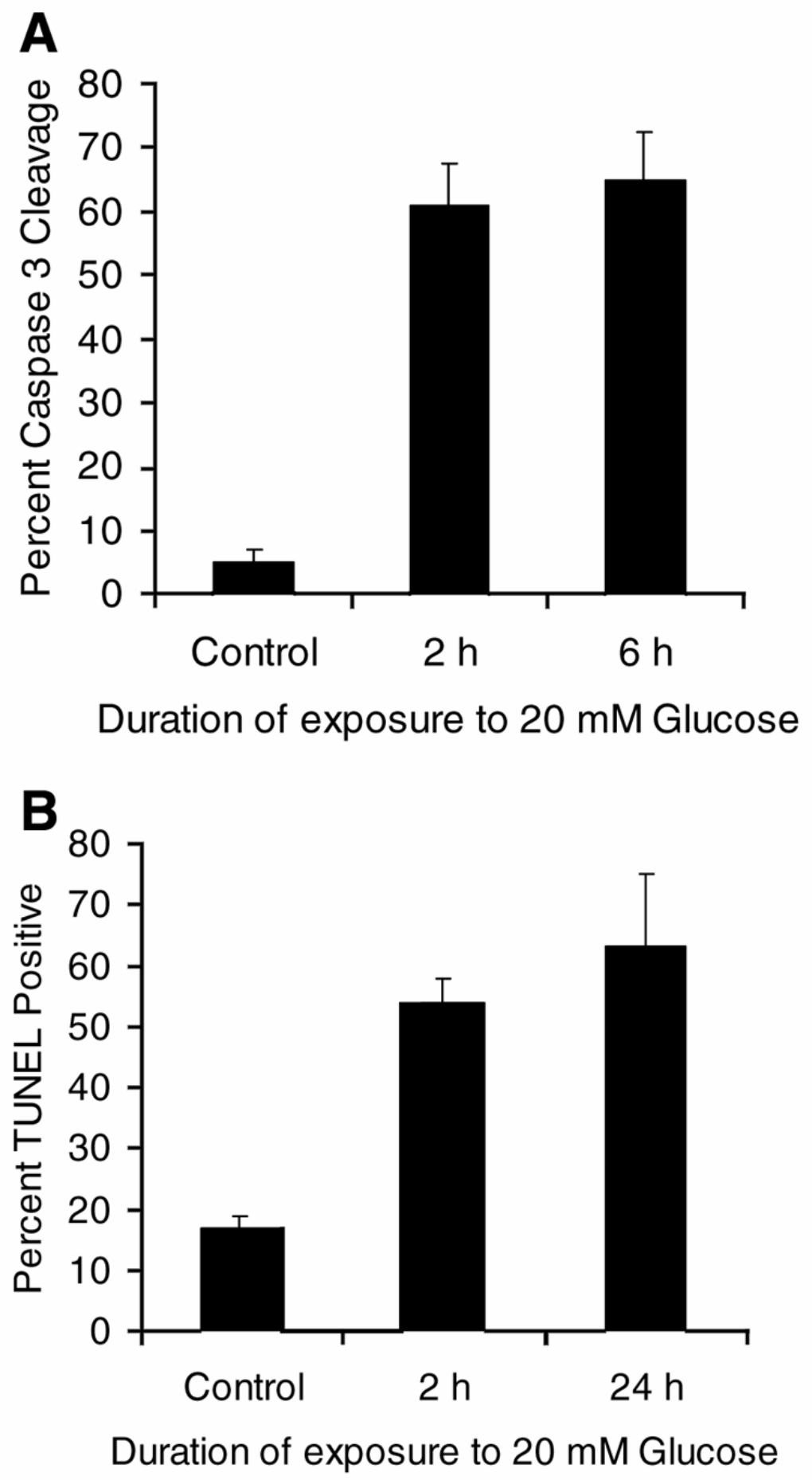

Figure 1. A 2 h exposure to hyperglycemia is sufficient to induce DRG neuron cell death. Glucose (20 $\mathrm{mM}$ ) was added to DRG neurons and either removed after $2 \mathrm{~h}$ or left for the duration of the experiment. In $\boldsymbol{A}$, DRG neurons were fixed after $6 \mathrm{~h}$ and stained for cleaved caspase-3. In B, DRG neurons were fixed after $24 \mathrm{~h}$ and TUNEL stained. There is no difference in caspase- 3 cleavage between 2 or 6 h hyperglycemia. Similarly, there is no difference in TUNEL positivity between 2 or 24 h hyperglycemia. 
Fig. 2

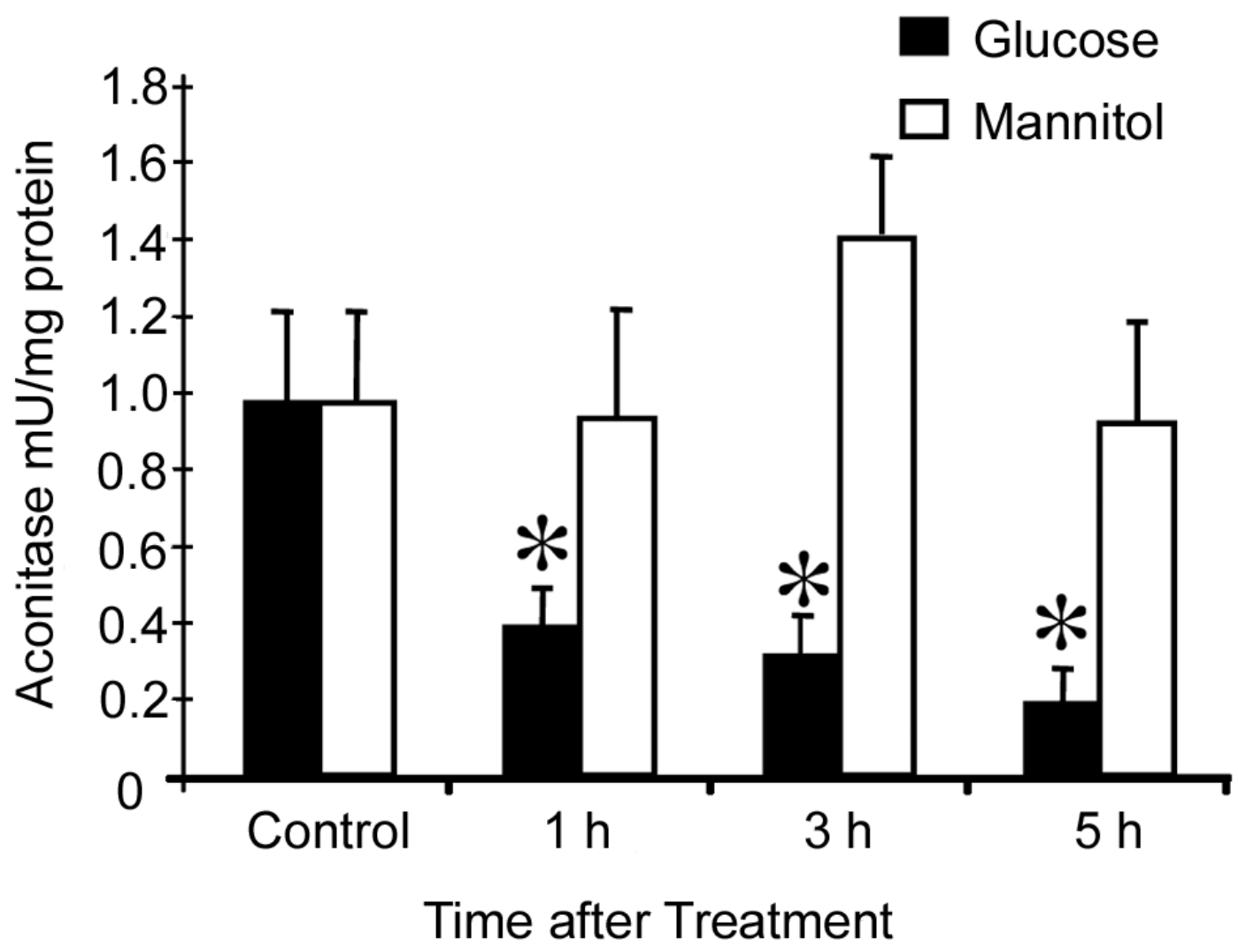

Figure 2. Aconitase is rapidly inhibited by hyperglycemia in DRG neurons. Aconitase activity was measured in DRG neurons over time after application of $20 \mathrm{mM}$ glucose or $20 \mathrm{mM}$ mannitol as an osmotic control. *Aconitase activity is significantly decreased compared with untreated control cells within $1 \mathrm{~h}$ and continues to decrease over $5 \mathrm{~h}, P<0.01$. 
Fig. 3
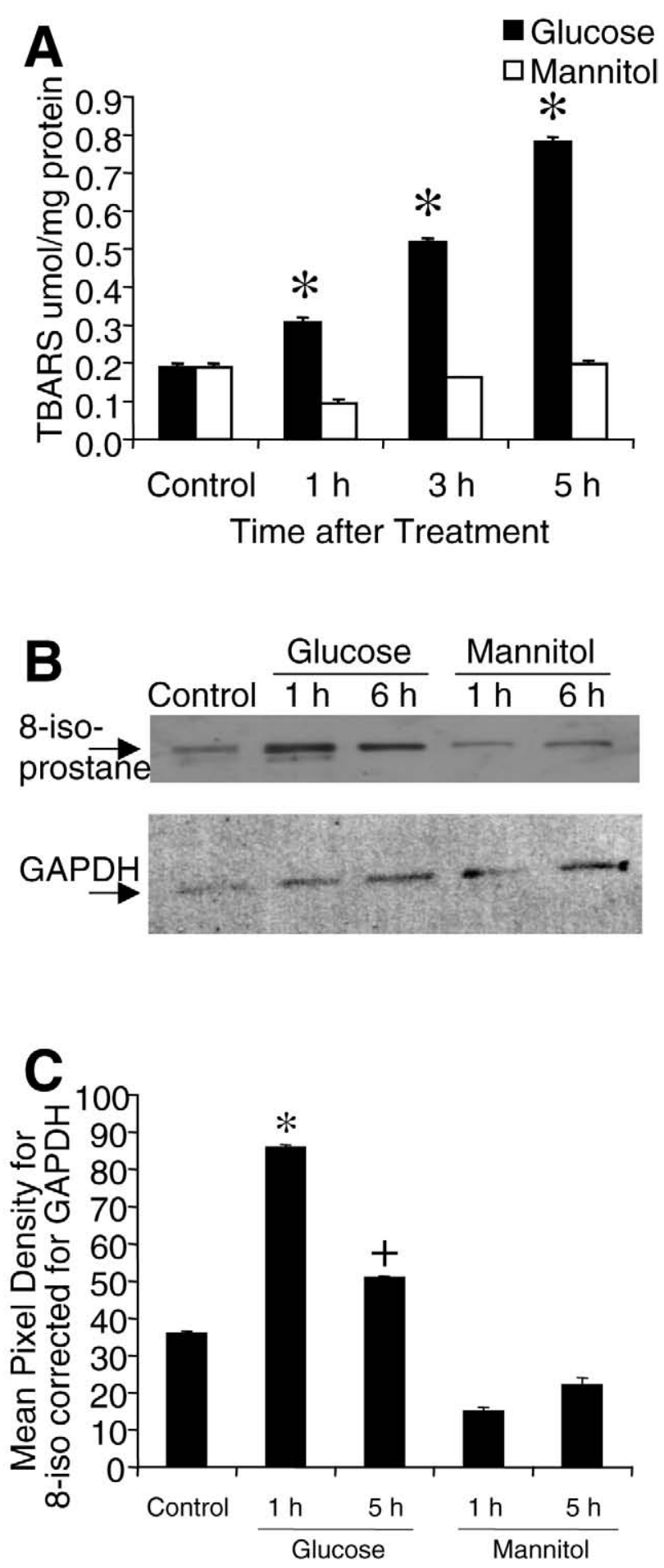

Figure 3. Lipid peroxidation increases within $1 \mathrm{~h}$ after hyperglycemia in DRG neurons. $A$ ) TBARS assay demonstrates that MDA increases significantly within $1 \mathrm{~h}$ of adding $20 \mathrm{mM}$ glucose compared with untreated control cultures, $P<0.05$. TBARS continues to increase significantly between $1-3$ and $3-5 \mathrm{~h}, P<0.05$. In contrast, $20 \mathrm{mM}$ mannitol does not alter TBARS in DRG neurons. B) Comparison of 8-isoprostane F2 $\alpha$ in untreated control cultures with 1 or $6 \mathrm{~h}$ exposure to $20 \mathrm{mM}$ glucose demonstrates a significant increase within $1 \mathrm{~h}$ that remains elevated at $6 \mathrm{~h}$. This effect is not present with mannitol treatment. Membranes were reprobed with GAPDH as a loading control. $\boldsymbol{C}$ ) Blot illustrated in $\boldsymbol{B}$ is analyzed by densitometry. Corrected mean pixel density for $1 \mathrm{~h}$ exposure to $20 \mathrm{mM}$ glucose is 3-fold higher than in control $(P<0.001)$. At $5 \mathrm{~h}$ after the application of $20 \mathrm{mM}$ glucose, 8 -isoprostane F2 $\alpha$ remains higher than control $(P<0.05)$. 
Fig. 4
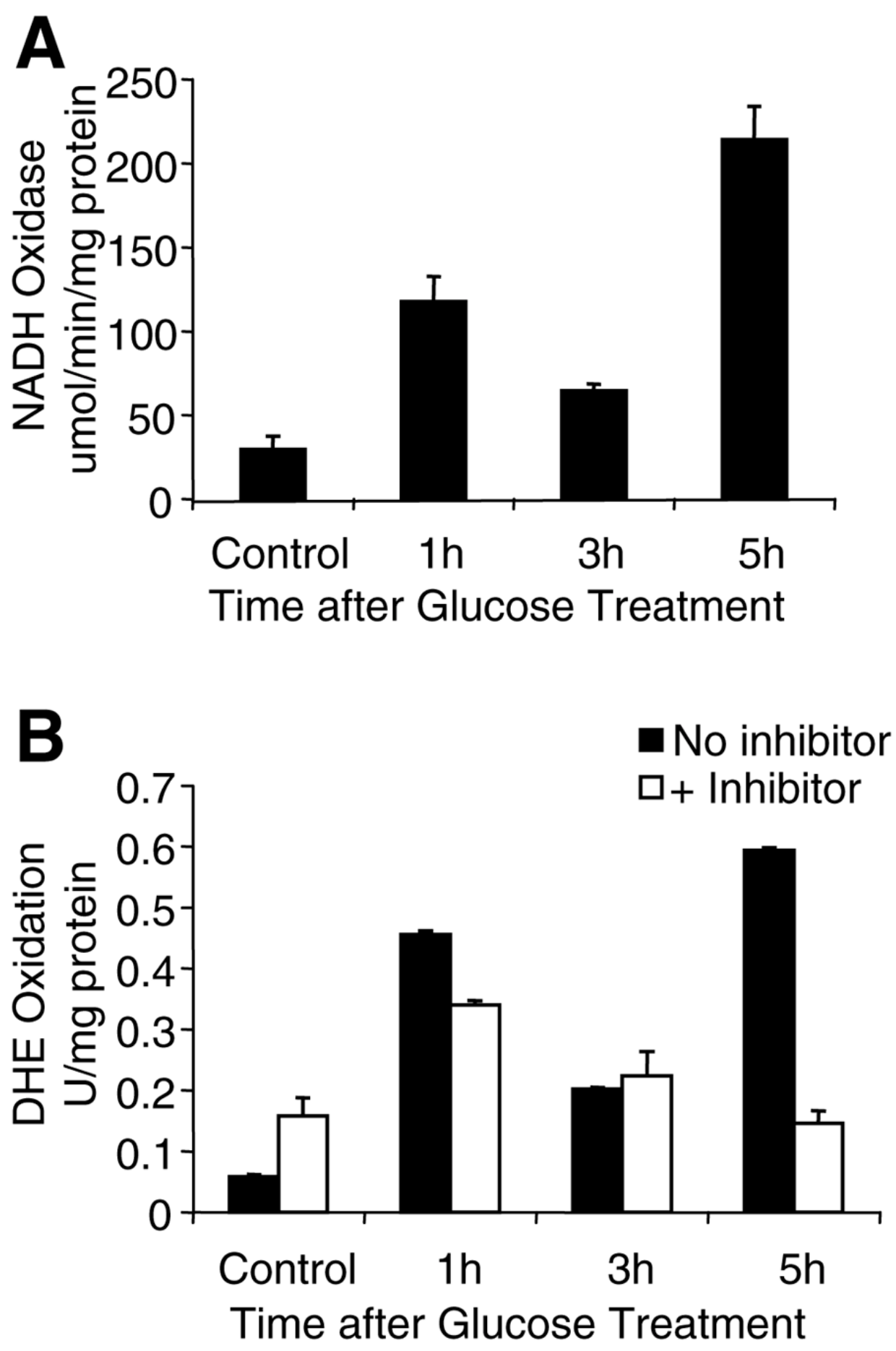

Figure 4. NADH oxidase is activated after hyperglycemia in DRG neurons. $\boldsymbol{A}$ ) NADH oxidase actively is measured in DRG neurons over time after application of $20 \mathrm{mM}$ glucose. Two peaks of activity are observed at $1 \mathrm{~h}$ and $5 \mathrm{~h}$ that are significantly higher than untreated control neurons $(P<0.01)$. B) The same lysates were assayed for NADH oxidase in the presence of DHE to assess superoxide production by the enzyme. Two peaks of superoxide are also observed on a similar time-frame but with different magnitudes of induction. The $1 \mathrm{~h}$ peak in NADH oxidase activity is a 5-fold increase, but the increase in DHE oxidation is 9-fold. The NADH oxidase inhibitor DPI $(100 \mu \mathrm{M})$ partially blocks $1 \mathrm{~h}$ peak in superoxide but almost completely blocks superoxide at $5 \mathrm{~h}$. 
Fig. 5
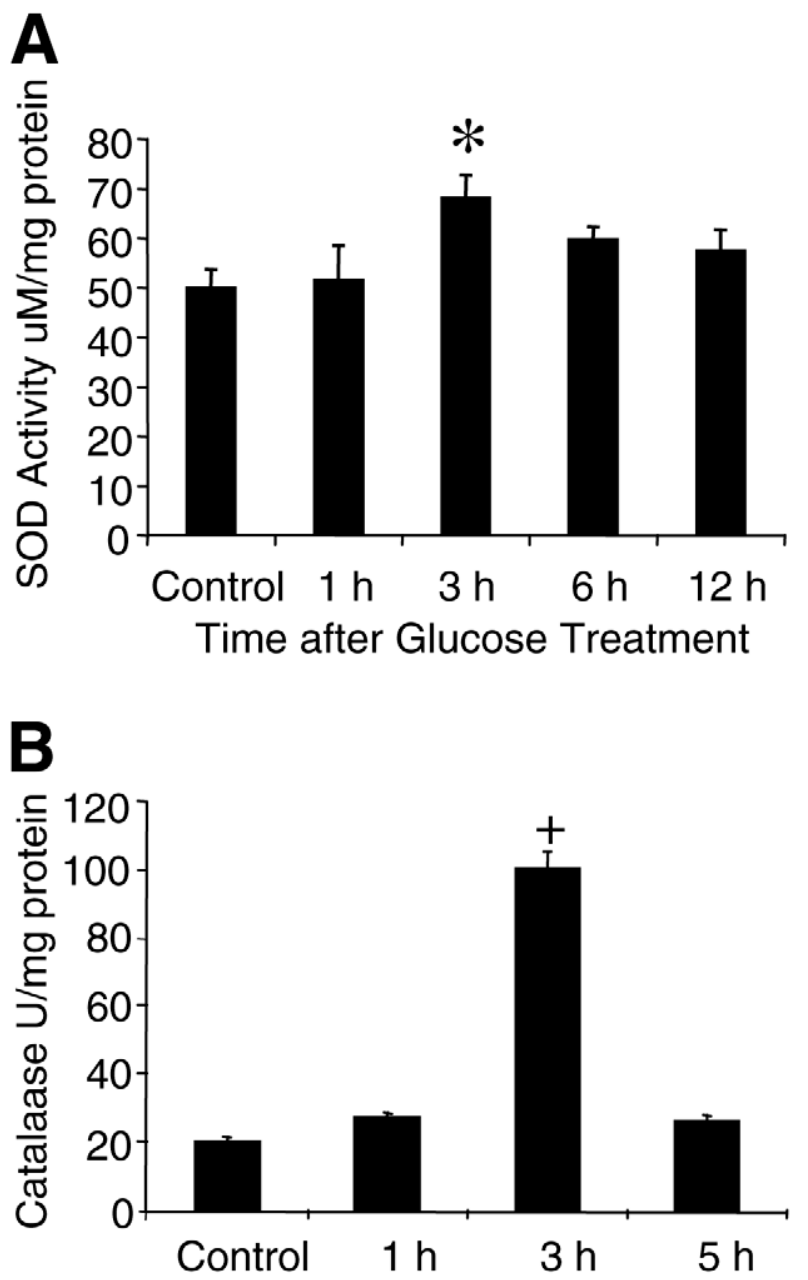

Time after Glucose Treatment

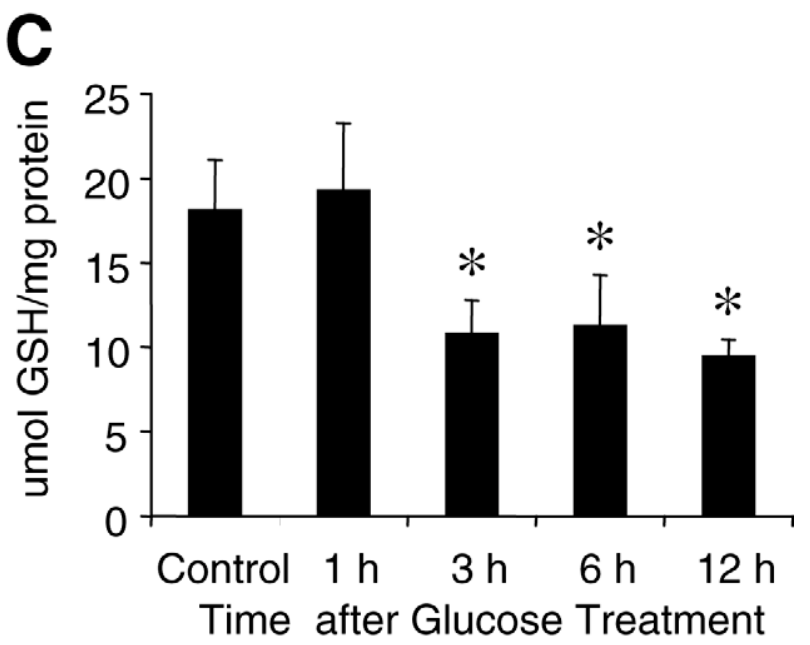

Figure 5. Antioxidant enzyme systems increase in response to acute hyperglycemia. DRG neurons were lysed after increasing periods of exposure to $20 \mathrm{mM}$ added glucose. Lysates were assessed for SOD activity $(\boldsymbol{A})$, catalase activity $(\boldsymbol{B})$, and concentration of reduced glutathione (GSH; $\boldsymbol{C}$ ). *SOD was significantly elevated at the $3 \mathrm{~h}$ time point only compared with untreated control neurons $(P<0.05)$. +Catalase was significantly elevated also at $3 \mathrm{~h}$ time point only compared with untreated control neurons $(P<0.01)$. GSH decreased moderately over time course examined $\left({ }^{*} P<0.05\right)$. 
Fig. 6
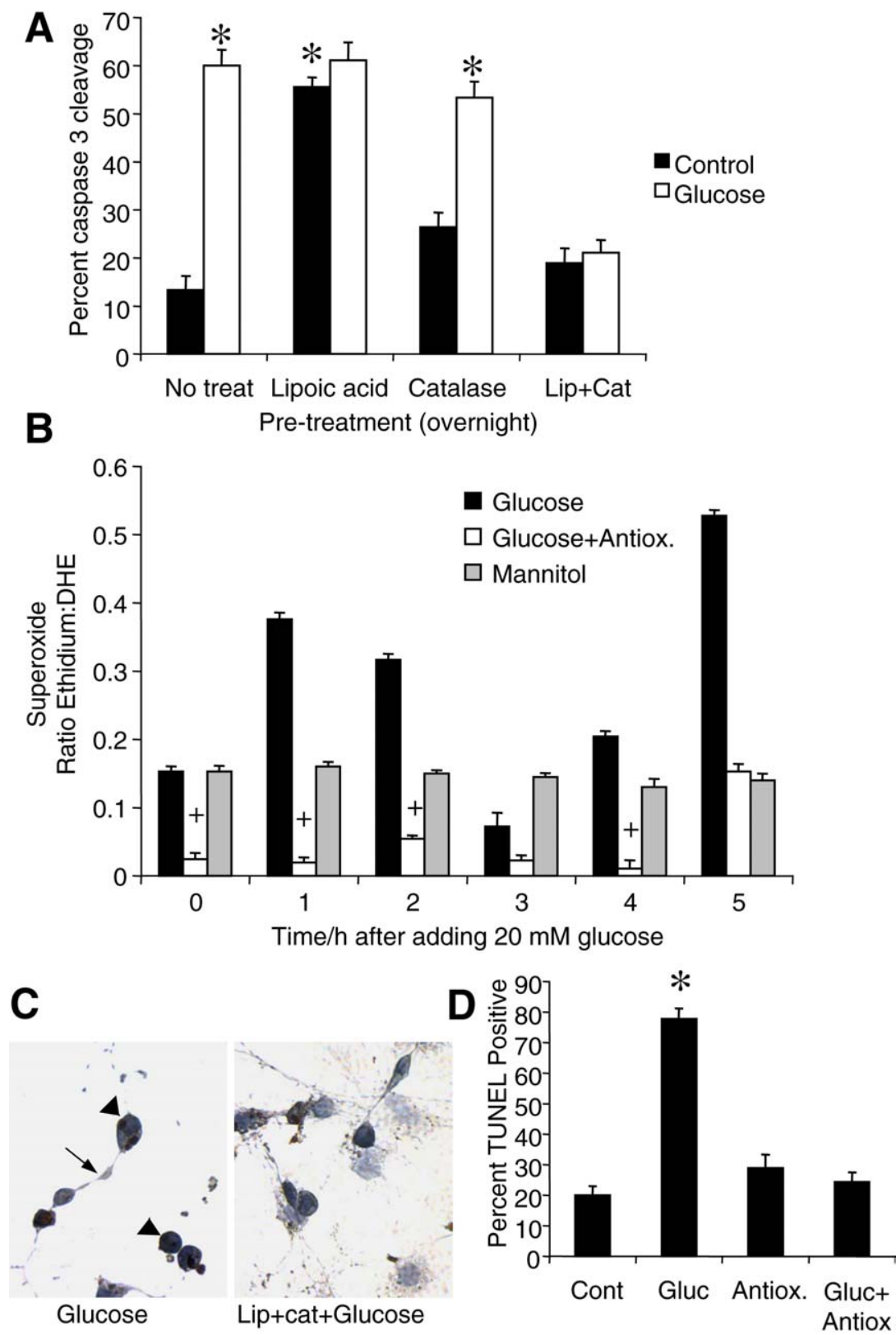

Figure 6. Exogenous antioxidants prevent glucose-induced oxidative stress and programmed cell death in cultured DRG neurons. A) Glucose-induced activation of caspase- 3 was assessed by immunohistochemistry in the presence of $\alpha$ lipoic acid $(100 \mu \mathrm{M})$ or catalase $(100 \mathrm{U} / \mathrm{ml})$ or both. *Glucose or $\alpha$-lipoic acid not treated with catalase significantly increased caspase-3 activation, $P<0.001$. B) Superoxide formation in intact DRG neurons was assessed by loading with DHE $(3 \mu \mathrm{M})$. Effects of glucose $(20 \mathrm{mM})$ alone, glucose plus $\alpha$-lipoic acid $(100 \mu \mathrm{M})$ and catalase $(100 \mathrm{U} / \mathrm{ml})($ glucose + antiox), and mannitol $(20 \mathrm{mM})$ on DHE oxidation were determined up to $5 \mathrm{~h}$. +Antioxidant treatment prevents both glucose-induced increases and basal levels of superoxide generation at $0,1,2$, and $4 \mathrm{~h}$. Mannitol does not alter superoxide generation in the DRG neurons. $\boldsymbol{C}$ ) Programmed cell death evidenced by DNA fragmentation (TUNEL assay) was determined in DRG neurons $24 \mathrm{~h}$ after glucose treatment \pm antioxidant treatment. The increase in TUNEL positivity (brown nuclei) by glucose was prevented in the presence of catalase-treated $\alpha$-lipoic acid. Evidence of condensed chromatin (arrowhead) and beading of neurites (arrow) also suggest that glucose-induced cell death involves programmed cell death. $\boldsymbol{D})$ Quantitation of the TUNEL staining in $\boldsymbol{C}$ demonstrates that glucose significantly increases DNA fragmentation in DRG neurons $(P<0.001)$, but application of catalase-treated $\alpha$-lipoic acid (Antiox) completely prevents glucose-induced programmed cell death. 
Fig. 7
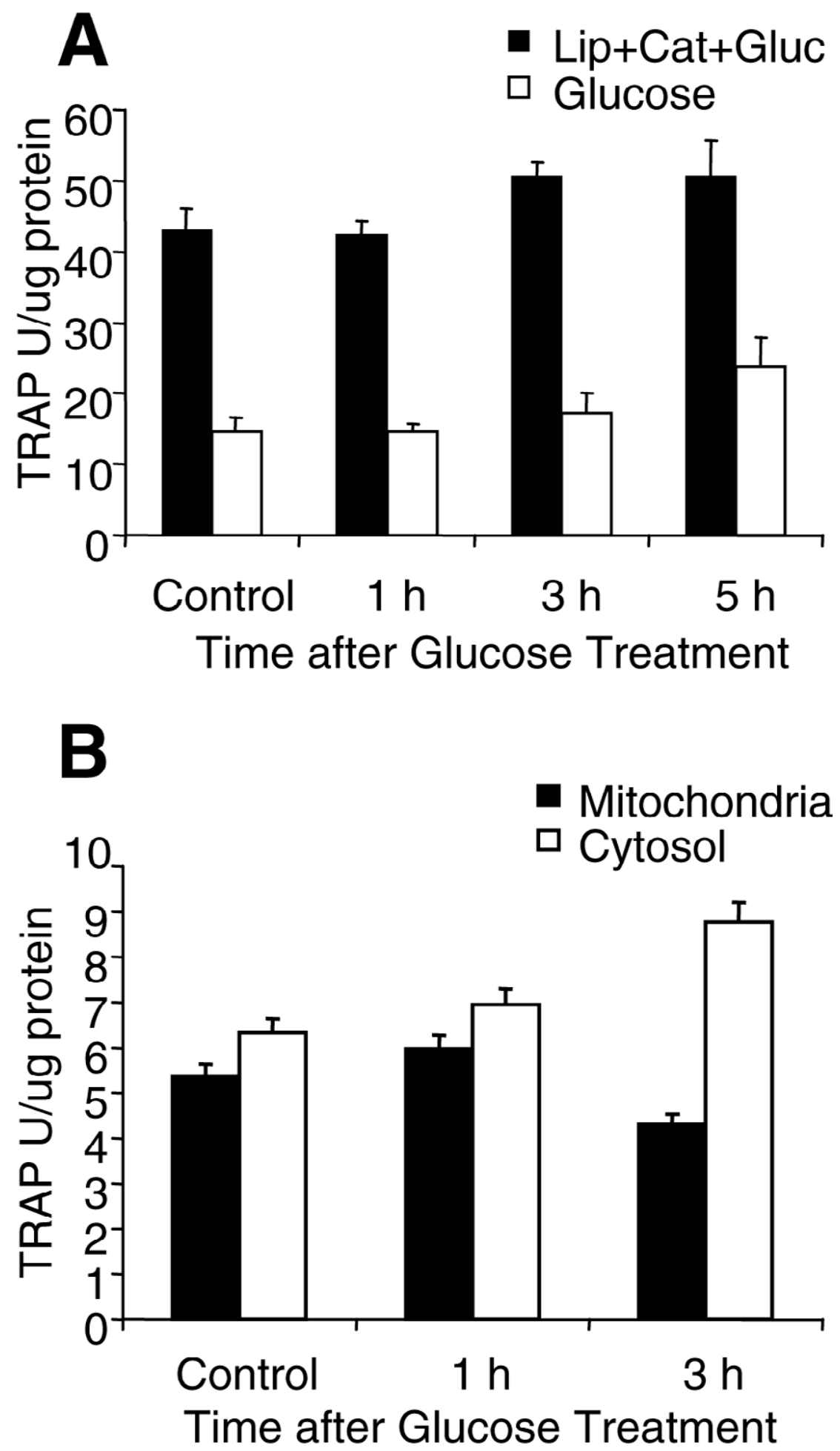

Figure 7. Total radical antioxidant potential (TRAP) is not decreased during acute hyperglycemia in DRG neurons. A) Whole DRG neuron lysates were assessed for the ability to prevent ABAP-induced oxidation of luminol at increasing periods after the application of $20 \mathrm{mM}$ glucose. Pretreatment with antioxidant combination of catalase-treated (100 U/ml) $\alpha$-lipoic acid $(100 \mu \mathrm{M})$ increased basal TRAP 3-fold. Over the time course of application of $20 \mathrm{mM}$ glucose, TRAP slightly increased in the presence and absence of the antioxidants. B) DRG neurons were separated into mitochondrial or cytosolic fractions by ultracentrifugation before TRAP assay. A differential effect of glucose application is seen in these 2 fractions, although the results do not reach statistical significance. 
Fig. 8

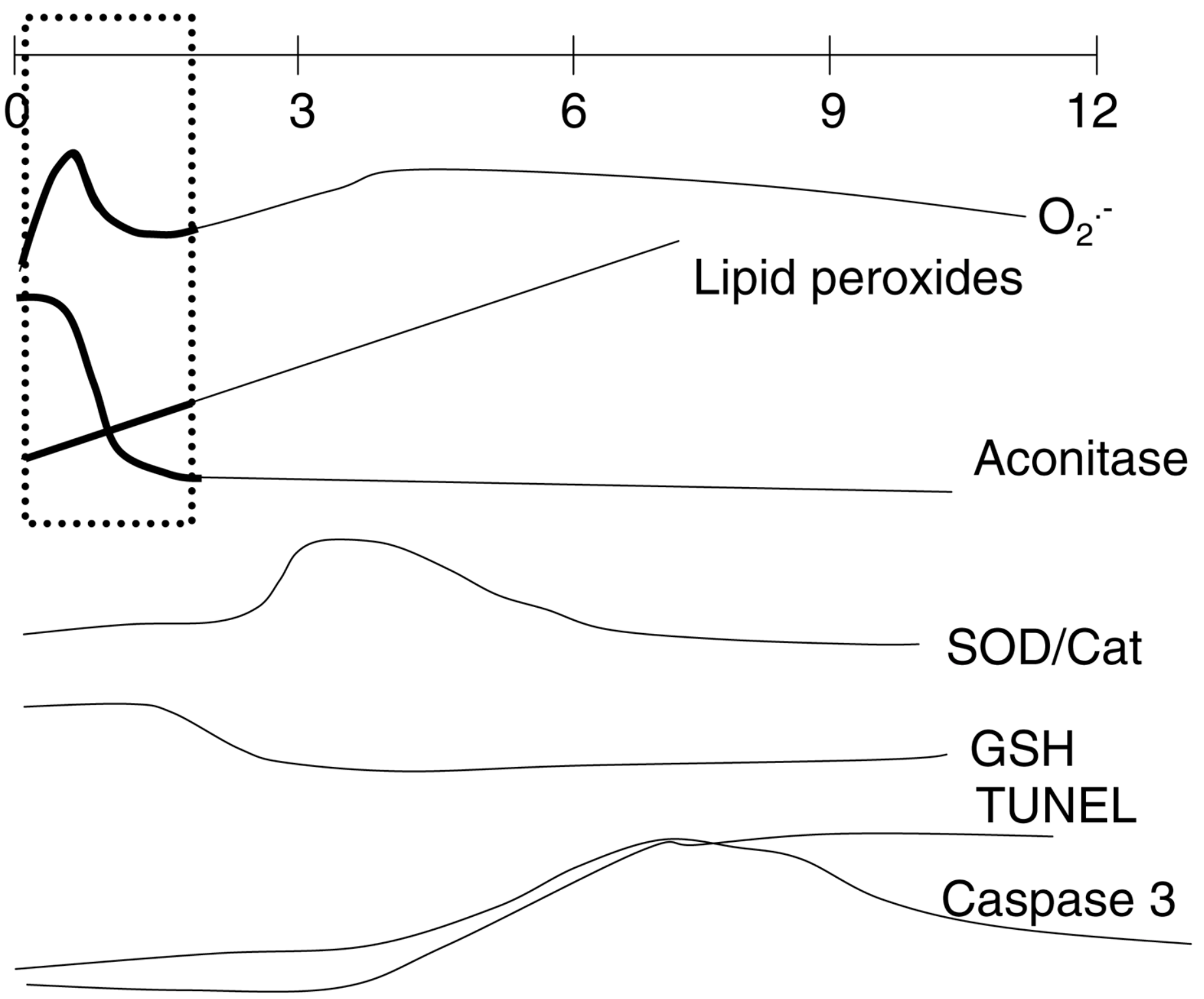

Figure 8. Time course of oxidative stress, antioxidant response, and cell death in DRG neurons treated with high glucose. By comparing time lines of experiments described in this study, we observe that the $2 \mathrm{~h}$ period of hyperglycemia that is sufficient to induce DRG neuron death is associated with superoxide generation, early lipid peroxidation, and loss of aconitase activity. Antioxidant enzymes increase at a later time $(3 \mathrm{~h})$, and evidence of programmed cell death reaches significance even later at 4-6 h (7). Thus, it is rapid hyperglycemia-induced acute oxidative stress that leads to DRG neuron death. 